\title{
Synthesis and Characterization of Phenol Formaldehyde Resin as a Binder used for Coated Abrasives
}

\author{
V. Ganeshram ${ }^{1 *}$ and M. Achudhan ${ }^{2}$ \\ 1 Assistant Professor, Department of Mechanical Engineering, Bharath University, Chennai-600073; \\ ganeshram.mech@bharathuniv.ac.in \\ 2Associate Professor, Department of Mechanical Engineering, Bharath University, Chennai-600073; \\ achu_mtech@yahoo.in
}

\begin{abstract}
Resins are as binders generally used are phenol formaldehyde resin (resol) glue, urea formaldehyde and epoxy resin. The type of backing, bond and abrasive grain dictates the application area of a coated abrasive product. For heavy applications a combination of sturdier backing, strong bond and bulkier and sharper abrasive grains are a necessity. More than the backing and abrasive grain, it is the adhesive bond which decider the life and performance of coated abrasive. The strong bond usually used is phenol resin. The demand for a better performing product necessitates the development of stronger resins. The various types of binders used for coated abrasives have been studied. The performance of phenolic resin made with this modified composition is analysed. This work thus forms a basis for the development of a better resin by modifying the existing composition. The synthesis and characterization of phenol formaldehyde resin as a binder used for coated abrasives was studied and found to be suitable for different applications in the industry.
\end{abstract}

Keywords: Resins, Grains, Backing, Binders, Phenol Formaldehyde.

\section{Introduction}

Abrasives are ceramic products that are used for material removal polishing and finishing operations across a variety of applications such as fabrication, automobiles, auto components, construction, wood working and general engineering applications [1]. Abrasives are broadly classified into two types, namely Bonded Abrasives \& Coated Abrasives. Bonded abrasives are used for heavy material removal operations like finishing as well as polishing in automotive, construction, fabrication, and steel bearing industries. Some of their characteristics are; three- dimensional, unflexible, Multi-layer grain coating, two-component system, dressing necessary, needs safety equipment. Coated abrasives are used for light material removal operations like in

${ }^{*}$ Corresponding author:

V. Ganeshram (ganeshram.mech@bharathuniv.ac.in) light polishing, tannery, plywood, scrubber pads and sand paper. Some of its features are: two-dimensional, flexible and cheap, single layer grain coating, three-component system, dressing not necessary.

\subsection{Raw Material Combination}

Different combinations of raw materials possible for coated abrasives are as shown in Figure 1.

For Raw Material Testing, the following has to be done: Adhesive was tested for its Viscosity and Melting point, Grain was tested for its Grit size and Size distribution, Backing Material was tested for its GSM, Stiffness, Tensile Strength and Absorption and Drying properties. Abrasive Grains are of two types based on occurrence [2]. 


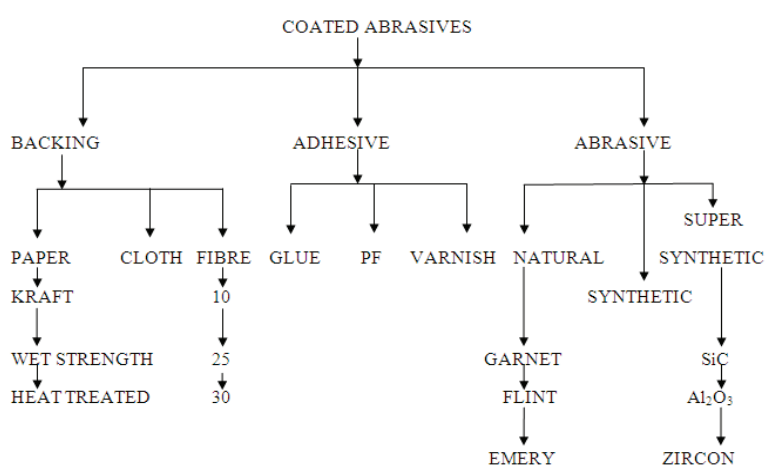

Figure1. Different combinations of raw materials possible for coated abrasives.

\subsubsection{Natural Abrasives}

Abrasives obtained naturally includes Emery and Garnet. Emery is a dark granular rock consisting of intimate mixture of corundum $\left(\mathrm{Al}_{2} \mathrm{O}_{3}\right)$ and magnetite $\left(\mathrm{Fe}_{3} \mathrm{O}_{4}\right)$ and hematite $\left(\mathrm{Fe}_{3} \mathrm{O}_{3}\right)$ together with impurities of titania, magnesia and silica. A small quantity of emery is used in coated abrasive products. It finds major use in non-skid, wear-resistant floors and pavement Garnet is the name given to a group of silicate materials possessing similar physical properties and crystal forms, but differing in chemical composition. Its use as a sandblast medium reduces risk of silicosis and also finds use in water filtration.

\subsubsection{Artificial Abrasives}

Produced synthetically and includes aluminum oxide, silicon carbide and zirconia. Fused alumina of controlled friability was obtained from bauxite. The fusion and slow cooling of a mixture of bauxite, coke and iron turnings give a coarse crystalline product of about $95 \% \mathrm{Al}_{2} \mathrm{O}_{3}$ and $0.7 \%$ titania, designated regular $\mathrm{Al}_{2} \mathrm{O}_{3}$. By adding more coke to charge, greater reduction is obtained and percentage of residual. Titania is reduced producing semi-friable alumina $\left(97 \% \mathrm{Al}_{2} \mathrm{O}_{3}\right)$. This material is less tough than regular alumina. After crushing, further heat treatment in rotary furnaces is used to alter the solubility of titania. Alumina fused in tilting furnaces and poured into ingots of sizes suitable for desired rate of cooling and resulting crystal size. During fusion process, much more friable abrasive is obtained. Major applications are cool cutting, self sharpening. It is produced from quartz sand and carbon in large electric furnaces in which charge acts as a refractory container. The temperature ranges from $1800^{\circ} \mathrm{C}$ to $2200^{\circ} \mathrm{C}$. Green and Black silicon carbide are produced.
Green silicon carbide is expensive and often preferred for tool grinding wheels. Black silicon carbide is preferred for grinding low tensile strength materials such as cast iron chilled iron-rolls, ceramics and aluminum. It is used as a wire-sawing abrasive in quarrying building stone. Fused zirconia is an excellent abrasive for heavy snagging of steel slabs and billets except for its cost density and lack of toughness [3]. Quick-cooled fusions of Zirconia and Alumina are widely used in large resin bonded snagging wheels for heavy-duty conditioning of steel slabs and billets and for weld-bead removal in pipeline construction. These materials are called AZ abrasives and used in coated abrasive application. It is not used in bonded abrasive because of thermal instability.

\subsection{Properties of Abrasive Grain}

\subsubsection{Hardness}

Hardness refers resistance to indentation. Hardness testing equipment involves equipment design to intent article being measured by a diamond point with result expressed in terms of knoop value. Table 1 gives the characteristics of Abrasive Grains.

\subsubsection{Fracture}

A Shape characteristic of mineral is very important in selecting abrasive grains. Electric furnace control and modern crushing techniques provides best possible sharp, wedge - shaped cutting surfaces. As the sharp edges of grain is worn away by friction and pressure build up proper fracture characteristics causes grain to refracture; thus exposing new cutting edges. Table 1 shows the grain shape of various abrasive grains [4].

\subsubsection{Toughness}

Besides ability to penetrate an object, an abrasive material must have sufficient resistance to shearing or breaking down, so that initial penetration may continue through out its use. If a mineral were hard enough to cut into a material, but through brittleness should break un-rapidly, its use wouldn't be economical. It is the ability to resist fracture under heavy loads is termed as toughness. Friability: Ability of an abrasive to fracture and expose new sharp points within same grain is called friability. Adorable grain can withstand high forces in the grinding operation without catastrophic wear. Durability and friability are not exactly opposites, as some durable grains exhibit microstructure to expose new sharp cutting points. Friable Abrasives fracture 
readily maintain sharpness and have less chance for metal damage.

\subsubsection{Chemical Reactivity}

Any chemical interaction between abrasive grains and material being abraded effects abrasion. Endurance scratch tests made on polished glass and iron rolls using conical grains of $\mathrm{Al}_{2} \mathrm{O}_{3} \& \mathrm{SiC}$ showed that $\mathrm{SiC}$ produced a long scratch path on glass roll and short path on steel roll. These effects were explained by reactivities of the two abrasives towards glass and steel, whereas $\mathrm{Al}_{2} \mathrm{O}_{3}$ is attacked by glass and inert to steels [5].

\subsubsection{Thermal Conductivity}

Abrasive mat may transfer heat from cutting tip of grain to bond posts, retaining the heat in coated belt or bonded wheel. Cooler the cutting point, harder the abrasive. Fused zirconium oxide has a low thermal conductivity, compared to other abrasive materials. It has a lower hardness that $\mathrm{Al}_{2} \mathrm{O}_{3}$ yet it performs quite well on hard to grind materials. This is attributed to the decreased heat flow from grinding interface into the grain (whose hardness decreases as it temperature rises) and to bond (subject to heat degradation).

\subsubsection{Melting Temperature}

Instantaneous grinding temperatures may exceed $3500^{\circ} \mathrm{C}$ at interface between an abrasive and work piece being ground. Hence, melting temperature is an important property. $\mathrm{Al}_{2} \mathrm{O}_{3}, \mathrm{SiC}, \mathrm{B}_{4} \mathrm{C}$ hardness decreases rapidly with increasing temperature. Ferrous metals also soften with increasing temperatures and do so even more rapidly than abrasives. So based on the temperature generated during application, proper abrasive cloth combination backings are used for manufacture of discs to provide a strong and shock resistant, sturdy support for coating.

\section{Binders}

\subsection{Phenol Formaldehyde Resins}

Phenols are a family of aromatic compounds with hydroxyl group bonded directly to aromatic nucleus. They differ from alcohols in that they behave like weak acids and dissolve readily in aqueous sodium hydroxide, but are insoluble in aqueous sodium carbonate. Phenols are colourless solids with exception of some liquid alkyl phenols. Melting point of pure phenol $\left(40.9^{\circ} \mathrm{C}\right)$ is lowered considerably by traces of water approximately $0.4^{\circ} \mathrm{C}$
Table 1. Types of Phenolic Resins

\begin{tabular}{|c|c|c|c|c|c|c|}
\hline Catalyst & Resin Type & $F / P$ & $\mathrm{~F}$ & $P$ & $\begin{array}{l}\text { Physical } \\
\text { State }\end{array}$ & $\begin{array}{l}\text { Product } \\
\text { Stability }\end{array}$ \\
\hline Base & Resole & $>1$ & $<2$ & $\leq 3$ & $\begin{array}{l}\text { Liquid, } \\
\text { solid } \\
\text { solution }\end{array}$ & Limited \\
\hline Acid & Novolak & $<1$ & 2 & $1.49-1.72$ & Solid state & Stable \\
\hline
\end{tabular}

per $0.1 \%$ of water content, over $6 \%$ renders, it as liquid at room temperature. Phenol is highly toxics and exposure limits, have to be strictly controlled. In the solid state, phenol is colourless. The chemistry of phenolic resins involves a variety of key factors which are critical in design of desired phenolic resin. These include: Molar ratio of formaldehyde (F) to phenol (P)Mode of catalysis : acid, base, metal salt Liquid, solid dispersion, Thermoplastic or Thermo synthetic resin [6].

Table 2 indicates the Phenol-Formaldehyde reactions lead to a heat reactive resole or stable novolak which depends upon mode of catalysis and molar ratio. These low to medium molecular weight material can be viewed as "Reactive Intermediates" which can be cured or can undergo many transformation reactions by appending new reactive groups to phenolic hydroxyl substituent such as epoxy or form a new ring structure. Phenolic resins are obtained by step growth polymerization. Resol is prepared by the addition of excess formaldehyde to phenol under basic conditions and novolak is prepared by the addition of excess phenol to formaldehyde under acidic conditions [7].

\subsection{Curing of Phenolic Resins}

Due to their mode of preparation, different curing conditions are necessary to cross - link resole and novolak resins. Resoles are readily cured by acid, base or thermal conditions. Novolak require a source of formaldehyde which is usually hexa. In curing, molecular weight advancement occurs leading to a gel state (B-stage) intermediate, no longer soluble in precursor medium (water or alcohol) while solvent is volatilized. During heating, flexible phenolic intermediate increase in modulus and becomes rigid and cross linked. The mode of curing for the different functional groups is given in Table 3.

Complete cure of phenolic resole leads to a high modulus, high cross-link density and moderately high transition temperature $\left(150^{\circ} \mathrm{C}\right)$. Cured material exhibits excellent 
Table 2. Curing of Phenolic Resins

\begin{tabular}{ll}
\hline Functional groups & Mode of Cure \\
\hline Methylol, Phenolic (Resol) & Acid, Base, Thermal \\
Phenolic (Novolak) & Hexa \\
\hline
\end{tabular}

moisture resistance and heat. These features coupled with attractive economics are motivating factors for the use of phenolics in many applications. Phenol formaldehyde resins are very exothermic and circumstances such as loss of cooling, loss of agitation and mischarge of catalyst or reactants can lead to uncontrollable self-heating conditions. Phenolics are superior when compared to other resins in case of high thermal insulation (thermal behaviour) which are used in brake and clutch linings and grinding wheels, high level of flame resistance, low smoke density and as a carbon donor in pyrolytic applications. They provide high carbon yields in various applications. Urea Formaldehyde Resins are the finished products, cross-linked (thermo-set) insoluble, infusible materials obtained from urea and formaldehyde. For application, a low molecular weight product or resin is first produced and then cross-linked only at the end of the fabrication process. In general comparison with phenolic resins, UF materials are cheaper, light in colour, lacking in odour, have better resistance to electrical tracking: Have an inferior heat resistance and a higher water absorption [8].

\subsection{Glues}

Glues are adhesives derived from collagen. The difference between gelatin and glue is the degree of purity, glue being impure gelatin (possibly of lower molecular weight also). Glue cannot be obtained from such non collagen proteins such as hair, horns and hooves. Glue is frequently used to refer any adhesive material irrespective of source or type. Dry animal glue, whether derived from hides, skins, bones is an amber coloured material. There are two principal types namely hide glue which is stronger and versatile and bone glue. Glue absorbs water readily, forming an elastic gel or viscous solution having great adhesive properties. Glycerol is the only other known solvent for animal glue and even it requires the presence of some moisture to effect solution. The most characteristic property of animal glue is its tendency to form reversible gels in aqueous solution. The largest single use of glue in the paper trade is in the production of gummed sealing tape. Its value here is due to its ability to absorb sufficient water to liquefy long enough to present a wet adhesive surface. While tape is being applied, than quickly to absorb water until the liquid gels and a firm bond is created .Hide glues are widely used in the manufacture of printer's rollers and padding glues [9]. The strength of their bonds also makes them useful for wood joining, for the manufacture of abrasives and abrasive wheels and for textile and paper sizing. Hide glue finds wide application, as an adhesive. Bone glues are used where the greater strength of hide glues is not required. Example, in adhesives for laminations, in sizes for the coating of paper and textiles, in the gummed labels and tapes for remoistening purposes. Glue form good bonds only with certain materials, particularly with cellulosics such as wood and paper. A characteristic proteinaceous odour is produced by strong heating.

\subsection{Alkyd Resins}

The term alkyd designates the resinous reaction products of di and polyhydric alcohol and acid. It includes all thermoplastic and potentially thermosetting polyesters, both saturated and unsaturated. Alkyd resin is made from a combination of phthalic anhydride and glycerol. Phthalic anhydride and glycerol will react at a temperature of about $160^{\circ} \mathrm{C}$ to form a liquid resinous product, which gradually increases in viscosity as heating continues until gelation suddenly occurs. When cooled, the product is hard, clear and brittle and is insoluble and infusible. In the first state, normal chain growth proceeds predominantly by the reaction of more reactive primary hydroxyl groups of glycerol with the dicarboxylic acid present. When approximately one third of the free acid remains, esterification continues with a slow decrease of acid content and production of the resin in the gelled or insoluble state. During the latter process, the effects of a slight increase in esterification are noticeable by the rapidity with which the molecular weight increases and with which the solubility and fusibility decrease as the amount of cross linking increases. Alkyd resins are usually modified with drying or non-drying oils and both natural and synthetic resins. More than one alcohol or acid may be used in the same alkyd resin to obtain special properties. The use of these modified resins is in surface coatings. When laid down as a film, the solvent evaporates and the residual resin cures by thermal or oxidative polymerization to a cross linked, insoluble form. The major properties of alkyd resins are faster drying, better water resistance and maximum colour retention. 
Alkyd resins find application in Enamels, lacquers, textile finishes, metal Primer and water emulsion paints. The products may be applied be spraying, brushing, dipping and roller coating technique [10]. Latex comprises colloidal and polymer chemistry in its preparation. In emulsion polymerization, hydrophobic monomers are added to water, emulsified by a surfactant into small particles and polymerized using a water soluble initiator. The result is a colloidal suspension of fine particles, $50-1000 \mathrm{~nm}$ in diameter, usually comprising of $30-50 \mathrm{wt}$ $\%$ of latex product. The reaction mass viscosity remains low throughout polymerization, providing for improved heat transfer agitation and product handling. The sensible heat of the water in the emulsion balances the heat of reaction generated by free radical polymerization and rate of reaction is rapid, while producing very high molecular weight. Some of the observable properties of latex are Stability, Substrate adhesion, Interfacial reactivity, Film forming ability. These properties are determined by the colloidal and polymeric properties of the latex particles. The potential value of most polymers can be realized only after proper compounding. Materials used to enhance polymer properties or reduce polymer cost include.

\subsection{Antioxidants}

Essential to retard degradation in unsaturated polymers. Cross Linking Agents: Used to build modulus, resistance to permanent deformation and greater solvent resistance in polymers. Accelerators: Frequently used to reduce time and temperature required to effect cross-linking. Fillers: Used for reducing the cost and to adjust processing rheology. Filler is any substance, either organic or inorganic, which is blended with a resin, to produce a homogenous mixture which can subsequently be moulded. The primary purpose in adding a filler is to improve physical properties of the molded article. The filler to a great extent controls the mechanical and strength properties of finished molded product and to a lesser extent it affects the electrical and heat resistance properties. The resin itself must give the proper flow and proper bond and must cure in a reasonable length of time. Of the fillers used in molding compounds, following may be mentioned; cellulose derivatives, lignin, proteinaceous fillers and mineral fillers (including carbon, asbestos, mica, metal salts and oxides). Since the fillers just described are organic none of them yields molded articles possessing high heat resistance. For this purpose, mineral fillers such as diatomaceous earth, or still better, mica or asbestos are preferable. Mica is used to improve heat resistance, dimensional stability, and electrical properties. It is superior to untreated asbestos for this type of service and at same time imparts excellent water resistance. Graphite is often used to improve frictional characteristics of phenolic parts. Fillers for laminated phenoplasts differ from those used in molding powders, in that the fillers for the former are usually continuous webs rather than discrete particles. Chemical nature of fillers is quite similar. Active fillers as those, which, based on physical and chemical reactions, cause an increase in the service life of the abrasive grain and lead to a cooler abrasion (temperatures which arise during grinding are kept at a lower level). Advantage is that cutting surface is smoother, therefore improved surface quality results [11].

\section{Experimental Part}

\subsection{Synthesis of Resole}

Phenol and formalin in 1:1.3 ration and 50\% sodium hydroxide solution were charged to a three necked flask equipped with a stirrer, reflux condenser and a thermometer. The refractive index of the solution was found at $25^{\circ} \mathrm{C}$. The mixture was heated to $60^{\circ} \mathrm{C}$ and the temperature was allowed to rise to $100^{\circ} \mathrm{C}$ over a period of about $30 \mathrm{~min}$ utes, if necessary temperature was adjusted by cooling with water. The reaction mix was then allowed to react for a further 15 minutes period. Following this reaction period, resin was vacuum distilled until the viscosity was about $2000 \mathrm{M} \mathrm{Pa}$ at $20^{\circ} \mathrm{C}$.

\subsection{Characterization of Resole}

\subsubsection{Non-Volatile Content}

Aluminum foil cup was taken and it was weighed. 2 to 5 gms of the sample was transferred and kept in an oven at $135^{\circ} \mathrm{C}$. After 3 hours, it was cooled and again weighed. Then, the percentage of non-volatile content was found out by the difference in weight.

\subsubsection{Water Tolerance}

$10 \mathrm{Gms}$ of the sample was weighed in a beaker. Water was added to the sample and it was stirred well. The water content was increased till turbidity occurs. The water tolerance was found by the amount of water required to cause turbidity. 


\subsubsection{Gel-Time}

Gel time is found out by gel-time meter. The temperature was set for $121^{\circ} \mathrm{C}$ in get time meter and is filled with liquid paraffin till the brim of the container. The heating system and stirrer were switched on. 10 gms of the sample was weighed and it was taken in a test tube and it is placed vertically in hot paraffin bath using wooden holder. Resin level in the tube was taken such that it was well within hot bath. A glass rod is placed in test tube and it was locked to the spindle drive with magnetic couple. The spindle was now rotated. When the top spindle rotates, magnetic coupling and bottom fin also start rotating along with glass rod. When the resin starts solidifying, rotation of glass rod was resisted, which in turn stop rotation of bottom fin. Upper fin, still rotating freely, will come into contact with static one, and the time was noted from the stopwatch. The gel-time was found out [12].

\subsubsection{Viscosity}

Viscosity of the sample was found out by Brookfield viscometer. Spindle number was selected and the speed of motor was set. The temperature of the solution was measured using temperature probe. The spring cap was removed and the spindle was fixed. It was immersed upto the mark in the resin and then switched motor was on. Spindle rotates inside the solution and produces shear, which gives value of viscosity. It was found out at an temperature of $25^{\circ} \mathrm{C}$.

\subsection{Trial}

After synthesis and characterization of the resin, a trial based on the synthesized resin was carried out. The various raw materials chosen for the trial are backing. For trial, backing used was cloth. Adhesive - The resin synthesized was used as an adhesive both Maker coat and Sizer coat. Abrasive - Grain used for trial was brown aluminium oxide of grit size \# 60. Maker coat was prepared with the specified quantities of synthesized resin, filler, cutting agent and a solvent. The materials were then stirred for 15 minutes. Colourant was added in the maker. After preparing the mix, it was checked for viscosity using orifice viscometer (3/16") at a temperature of $30^{\circ} \mathrm{C}$ which is normally in the range of 30 secs. Water was added for viscosity adjustment of mix. Backing material was passed through two rollers, rotating in opposite direction. Bottom roller is immersed partially in drum containing maker mix. When the backing passes through roll, it gets coated and thickness of coating was adjusted by adjusting the gap between the rollers. After the maker coat was applied, grains are added to it, maker coat binds the abrasive grains with backing. After the grain coating, the material was dried in an oven for $1 \frac{1 / 2}{2}$ hours at a temperature of $80^{\circ} \mathrm{C}$. Weight of the solids content was found out for the maker mix. Also the non volatile content and viscosity were checked. The maker and sizer mix usually have same composition with some viscosity variation. The composition for a mix includes filler, resin and the solvent. As per the composition, the materials was weighed and stirred for 15 minutes. Viscosity of the mix is measured using an orifice viscometer. Non volatile content was fount out. After checking of viscosity of the sizer mix, it was applied to the backing material which was kept for drying in an oven. Sizer coat was applied to the backing material which was passed between the rolls, each rotating in opposite direction. Bottom roller was immersed partially in drum containing sizer mix. When the backing passes through the roller, it gets coated and the thickness of coating was adjusted by adjusting gap between rollers. After the application of sizer coat, it was kept in an oven for $1 \frac{1 / 2}{2}$ hours for drying at an average temperature of about $80-90^{\circ} \mathrm{C}$. After drying, curing was done for 80 hours at a temperature of $120^{\circ} \mathrm{C}$. Following curing, the abrasive sheets were brittle, so to reduce its brittleness, humidification is done. After humidification, flexing is done to control the breaking of bonds, thereby making the abrasive flexible. Coated sheets are passed through cylindrical bars for single flexing. The flexed sheet was then made into a converted product. One of the converted products made was belt with dimension of $50 / 2000$ at an angle of $45^{\circ}$.

\section{Manufacture of Coated Abrasive}

The flow sheet in Figure 2 shows the various steps involved in the manufacture of coated abrasive.

Printing: Large roll of desired backing is taken through printing side and printed with trademark, brand name, grade number etc. Maker Coating: Backing moves to receive first adhesive application called maker coat in a carefully regulated film. The concentration and quantity of adhesive is regulated according to particle size of mineral to be used. Film thickness is maintained by adjusting 


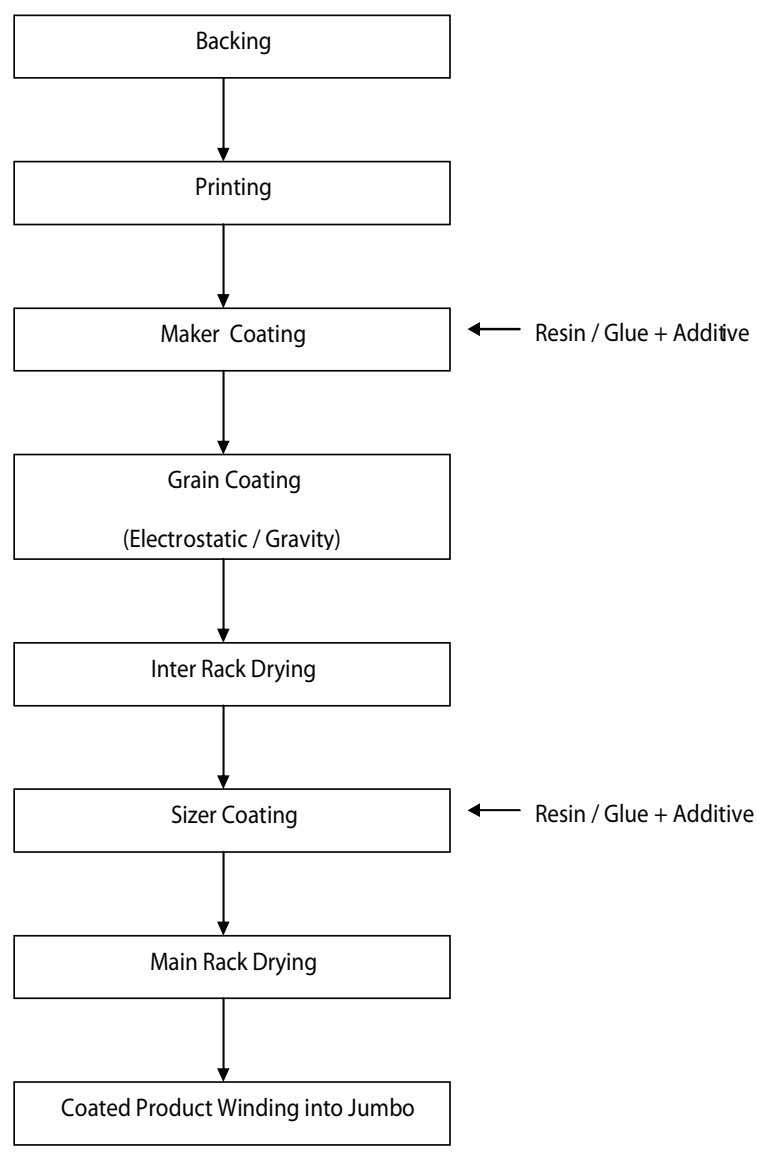

Figure 2. Flow sheet for the manufacture of Coated Abrasive.

gap between rollers through which backing proceeds. Grain Coating: Abrasive grains can be coated by gravity or electrostatic coating methods. Between a pair of electrode, backing with maker coat (top) and a continuous belt carrying grains (bottom) move in opposite direction and very high voltage ( 15 to $30 \mathrm{KV}$ ) is passed between these electrodes due to which grains are propelled from moving the belt to backing in such a way that sharp edges stick out. The amount of abrasive grains deposited on adhesive covered backing can be controlled with greater accuracy and can be varied from very sparse open coat to dense mass heavily studding sheet. Drying Inter - Rack: After grain coating the backing is carried by festoon conveyor to drying chamber $\left(2 \mathrm{hrs}\right.$ at $\left.75^{\circ} \mathrm{C}\right)$. Maker resin set and firmly holds the grains, so that they aren't lost during sizer application. Sizer Coating: Second application of adhesive bond called sizer coat is given. This coating unites with making film and is applied in degree necessary to anchor the grains securely. Drying Main

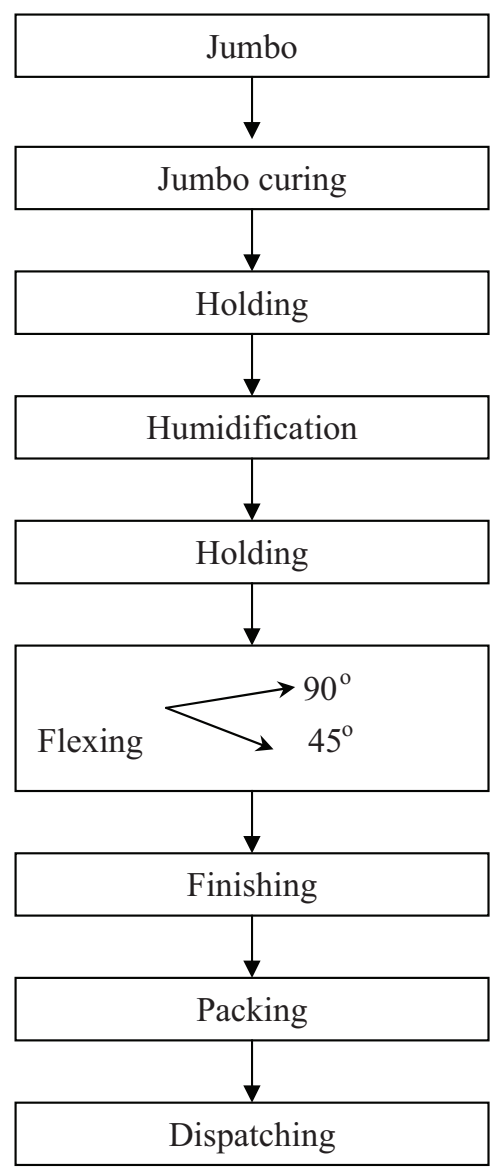

Figure 3. Flow sheet for conversion of coated abrasive.

Rack: After sizer application, the backing is again carried through festoon drier. It is dried around $75^{\circ} \mathrm{C}$ for cloth and fibre based products and $130^{\circ} \mathrm{C}$ for paper.

\section{Coated Conversion}

The flow sheet in Figure 3 shows the steps involved in the conversion of coated abrasives.

\subsection{Flow Sheet for Conversion of Coated}

\section{Abrasive}

\subsubsection{Curing}

Whenever resin is used as an adhesive, bond curing is must. As fibre and cloth receive resin coating, they are always cured. Curing is done to cause complete setting of maker and sizer and to enhance polymeric bond between them. Curing temperature is around $110^{\circ} \mathrm{C}$ and done for $36-80$ hours depending on application and nature of product. 


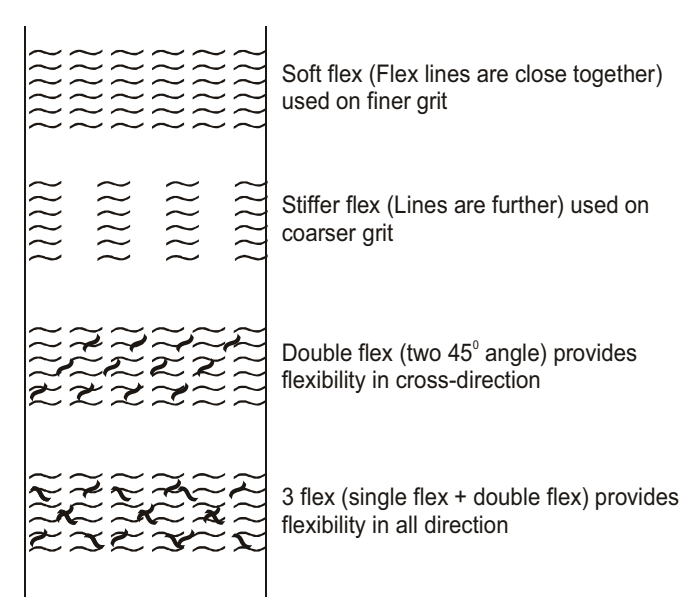

Figure 4. Types of flexing.

\subsubsection{Humidification}

After curing, jumbo is highly stiff, so as to reduce its brittleness, humidification is done. Steam is passed along printing side, so some hot moisture get into backing and makes it easy to handle. Steaming is done once or twice based on stiffness of backing.

\subsubsection{Flexing}

Coated abrasives are flexed to a degree required for particular operation intended. It is actually a controlled breaking of continuous bonded abrasives coating with some detrimental effect on the bond or backing.

A feature of breaking is to control spacing and direction of breaks. Here, jumbo is made to pass over a number of rolls and in different angles to make it hand liable. Based on the angle in which it is passed over rollers, it is classified into three types.

\subsubsection{Single flexing}

Flexing in $90^{\circ}$ angle machine (lengthwise) direction of coated abrasive is called single flexing. It leaves sheet stiff in one direction and flexible in another. If the flex lines are closer, it is called soft flex. If it is further, it's called stiffer flex.

\subsubsection{Bi flexing}

Flexing $45^{\circ}$ angle machine (lengthwise) direction of coated abrasive twice is called bi flexing. It gives all around flexibility. Triple flexing - Combination of single and biflexing is called triple flexing. It is used for sanding irregular con- tours. Conversion: Coated abrasive in jumbo form is made to products in the form useful to the customers like sheets, rolls, belts, discs by conversion.

\subsubsection{Sheet-Cutting}

A ream cutter, combination of slitter and a fly knife is employed to cut standard sheets of size 9" $\times 11$ ". Mostly paper backed products are made into sheet.

\subsubsection{Slitting}

Material intended for belts or some cut shapes are slit. Trimmed and narrow rolls are produced using a machine with circular knives moving against hardened stud roll, with rewinding of desired length.

\subsubsection{Disc Making}

In addition to production of individual preformed discs with grain coating, we can also produce discs from coated jumbo by disc cutting. Hence, slits of required width are taken to punch press where the disc, its central holes and required slots are punched in the operation.

\subsubsection{Belt Making}

Slit rolls of proper width are cut to required length plus amount of joint overlap by a knife, set at definite angle to a straight edge which aligns cloth abrasive strip. Usually cut angle is $45^{\circ} \mathrm{C}$ and based on the width of belt needed, cut angle can be varied. Generally Narrow belt requires a 30 acute angle and Wide Belt do not require Wide angle cuts at very great angle as it will not allow belt to run smoother. Two types of Joints are used in belt making namely Butt joint which is made by tape reinforcement at the back with two edges kept together. Though, they produce belts of uniform thickness they are mostly unsatisfactory on modern machine [12]. Lap joint where angle cut belt length goes through skiving machine where a layer of abrasives is removed. Single skiving is done for coarser grits. Double skiving is done for finer grits. Skiving was done for joining the ends using the tape called Mylor tape, which is made up of polyethylene and acetone as a solvent. Mix is prepared in a desmocoll mixer and is applied to the ends of belt to join. Adhesives of the highest quality are essential, because many belts run under moderate tension and extreme working pressures. These adhesives are applied to spliced areas from which the grain has been removed by skiving from the 
bottom part of the lap, then the other end of the belt is put on top of this area and splice is pressed until set [13]. Belts with coarser grit, where only one end which form the bottom part, product is skived. Done for other grits, where skiving is done on both the ends, so that thickness of lap joints is nearly same as that of belt thickness, this aids in smooth running of the machine. After skiving, feathering is done. Feathering is threading at ends to enhance gradual increase in belt thickness at ends, so that when two such ends are brought together belt thickness will be uniform even at joint and adhesive is then applied [14].

\section{Scope of the Project}

The type of backing, bond and abrasive grain dictates the application area of a coated abrasive product. For heavy applications a combination of sturdier backing, strong bond and bulkier and sharper abrasive grains are a necessity. More than the backing and abrasive grain, it is the adhesive bond which decider the life and performance of coated abrasive.

The strong bond usually used is phenolic resin. The demand for a better performing product necessitates the development of stronger resins. This has been tried by modifying the phenol to formaldehyde ratio in a phenolic resin.

The performance of phenolic resin made with this modified composition is analysed. This work thus forms a basis for the development of a better resin by modifying the existing composition.

\section{Result}

The belt prepared from the trial was subjected to the following tests to evaluate its performance. Work: The amount of material (work piece) removed when it is in contact with the abrasive is called work. It was found by weighing the mild steel rod. Wear: Initial weight of the belt is noted, and after finding the work rate, final weight of the belt was noted. Wear rate was determined from the difference in weight. Stretch: is the elongation of the belt after work and wear rate are determined.

When compared with results, the performance of the belt using synthesized resin was lesser than the already existing composition, so the ratio of phenol and formaldehyde has to be increased.

\subsection{Characterization of Resole}

\subsubsection{Non Volatile Content}

The non volatile content of the synthesized resin was found to be $81.98 \%$. The non volatile content of the already existing resin was found to be $83.75 \%$.

\subsubsection{Water Tolerance}

The water tolerance of the synthesized resin was found to be $165 \%$. The water tolerance of the already existing resin was found to be $200 \%$.

\subsubsection{Gel Time}

The Gel time of the synthesized resin was found to be 19 minutes 20 seconds. The Gel time of the already existing resin was found to be 16 minutes 10 seconds.

\subsubsection{Viscosity}

The viscosity of the synthesized resin was found to be 2500 cps. The viscosity of the already existing resin was found to be $6000 \mathrm{cps}$.

\subsection{Trial Studies}

\subsubsection{Maker Characteristics}

The maker mix was weighed as per the given composition and its characteristics were found out. The viscosity of the maker mix was found to be 29 seconds. The non volatile content of the maker mix was found out to be $88.75 \%$.

Table 3. The performance of the belt using synthesized resin

\begin{tabular}{|c|c|c|c|c|c|c|c|}
\hline \multirow{2}{*}{$\begin{array}{l}\text { Sl. } \\
\text { No. }\end{array}$} & \multicolumn{3}{|c|}{ Work } & \multicolumn{3}{|c|}{ Wear } & \multirow{2}{*}{$\begin{array}{c}\text { Stretch } \\
(\mathrm{mm})\end{array}$} \\
\hline & $\begin{array}{c}\text { Initial } \\
\text { weight } \\
\text { (gms) }\end{array}$ & $\begin{array}{c}\text { Final } \\
\text { weight } \\
\text { (gms) }\end{array}$ & $\begin{array}{c}\text { Work } \\
\text { rate } \\
(\mathrm{gms})\end{array}$ & $\begin{array}{c}\text { Initial } \\
\text { weight } \\
\text { (gms) }\end{array}$ & $\begin{array}{c}\text { Final } \\
\text { weight } \\
\text { (gms) }\end{array}$ & $\begin{array}{c}\text { Wear } \\
\text { rate } \\
\text { (gms) }\end{array}$ & \\
\hline 1. & 1331 & 1176 & 155 & 113 & 108.0 & 5.0 & Initial 2012 \\
\hline 2. & 1176 & 1058 & 118 & 108 & 106.3 & 1.7 & \\
\hline 3. & 1058 & 949 & 109 & 106.3 & 104.7 & 1.6 & \\
\hline 4. & 949 & 867 & 82 & 104.7 & 103.2 & 1.5 & \\
\hline \multirow[t]{2}{*}{5.} & 867 & 804 & 63 & 103.2 & 102.6 & 0.6 & Final 2004 \\
\hline & & & 527 & & & 10.4 & $\begin{array}{l}\text { Stretch } \\
8 \mathrm{~mm}\end{array}$ \\
\hline
\end{tabular}


Table 4. The performance of the belt of already existing composition

\begin{tabular}{|c|c|c|c|c|c|c|c|}
\hline \multirow{2}{*}{$\begin{array}{l}\text { Sl. } \\
\text { No. }\end{array}$} & \multicolumn{3}{|c|}{ Work } & \multicolumn{3}{|c|}{ Wear } & \multirow{2}{*}{$\begin{array}{c}\text { Stretch } \\
(\mathrm{mm})\end{array}$} \\
\hline & $\begin{array}{c}\text { Initial } \\
\text { weight } \\
\text { (gms) }\end{array}$ & $\begin{array}{c}\text { Final } \\
\text { weight } \\
\text { (gms) }\end{array}$ & $\begin{array}{l}\text { Work } \\
\text { rate } \\
\text { (gms) }\end{array}$ & $\begin{array}{c}\text { Initial } \\
\text { weight } \\
\text { (gms) }\end{array}$ & $\begin{array}{c}\text { Final } \\
\text { weight } \\
\text { (gms) }\end{array}$ & $\begin{array}{l}\text { Wear } \\
\text { rate } \\
\text { (gms) }\end{array}$ & \\
\hline 1. & 1342 & 1199 & 143 & 113.9 & 110.9 & 3 & $\begin{array}{l}\text { Initial } \\
2000\end{array}$ \\
\hline 2. & 1199 & 1101 & 98 & 110.9 & 110.5 & 0.4 & \\
\hline 3. & 1101 & 1018 & 83 & 110.3 & 110.0 & 0.5 & \\
\hline 4. & 1018 & 946 & 72 & 110 & 109.7 & 03 & \\
\hline \multirow[t]{2}{*}{5.} & 946 & 883 & 63 & 109.7 & 109.3 & 0.4 & Final 2009 \\
\hline & & & 459 & & & 4.6 & $\begin{array}{l}\text { Stretch } 9 \\
\mathrm{~mm}\end{array}$ \\
\hline
\end{tabular}

\subsubsection{Sizer Characteristics}

The sizer characteristics were weighed as per the given composition and its characteristics was found out. The viscosity of the sizer characteristics was found to be 25 seconds. The non volatile content of the maker mix was found out to be $86.28 \%$. Table 4 gives the Performance of the belt using synthesized resin and Table 5 gives the performance of the belt of already existing composition.

\section{Conclusion}

The composition of the phenol and formaldehyde was altered to a lesser extent and the resin was synthesized and characterized such that the performance of the product was compared between the already existing one and the synthesized one. The performance of the synthesized resin was not beneficial, so the composition has to be changed for a higher ratio.

\section{References}

1. Burton W E (1999). Design of tough epoxy resins in Polymer Toughening, Polymers and Resins, McGraw-Hill Book and Company, New York, 511-516.

2. D'Alelio (1952). Paint and coating testing manual, Fundamental Principles of Polymerization, John Wiley and Sons, New York, USA, 5-22.

3. Flory P J (1953). Copolymerisation, emulsion and ionic polymerisation, Principles of Polymer Chemistry, Cornell University Press, Ithaca, New York, 178-195.

4. Collie M J (1981). Abrasive materials, Industrial abrasive materials and compositions, Noyes Data Corp., 212-220.

5. Kirk, and Othmer, Encyclopedia of Chemical Technology, vol II, 1-880, vol 14, 1-224, vol 20, 1-223.

6. Ellis C (1935). Synthetic resins, The Chemistry of Synthetic Resin, Reinhold Publishers Company.

7. Coated Abrasive (2006). Available From: www.cumiabrasives.com.

8. Resin (2006). Available From: www.polymerplastics.com.

9. Brydson J A (2005). Phenolic resins, plastics material, Butterworth Heinemann, Oxford, New Delhi. 635-680.

10. Domininghaus H (1998). Phenolformaldehyde resins, Plastics for Engineering, Hanser Publishers, Munich, New York, 327-342.

11. Goodman S H (1996). Phenolic resins, Hand book of Thermoset Plastics, Noyes Publications, New Jersey, 1-7.

12. Newaz S S (1985). Intiators and Stablisers, Encyclopedia of Polymer Science and Engineering, Willy-Interscience Publication, New York, Singapore, vol 12, 3.

13. Goodman S H (2005). Hand book of Jaico Publishing House, Mumbai (2005).

14. Harper C A (2000). Liquid resin process, Modern Plastics Hand Book McGraw-Hill, New York, 529-570. 